\title{
A FORMAÇÃO DE PROFESSORES ALFABETIZADORES PARA A EDUCAÇÃ̃o INCLUSIVA̧: UM DESTAQUE AO PACTO NACIONAL PELA ALFABETIZAÇÃO NA IDADE CERTA
}

\author{
LA FORMACIÓN DEL PROFESORADO ALFABETIZADOR PARA LA EDUCACIÓN \\ INCLUSIVA: UN DESTAQUE AL PACTO NACIONAL POR LA ALFABETIZACIÓN \\ EN LA EDAD CIERTA
}

THE TRAINING OF ALPHABETIZING TEACHERS FOR THE INCLUSIVE EDUCATION: A HIGHLIGHT TO THE NATIONAL PACT FOR ALPHABETIZATION IN THE RIGHT AGE

\author{
Lucia Cristina Dalago BARRETO' \\ Elsa Midori SHIMAZAKI²
}

RESUMO: Este estudo analisa as contribuições do Pacto Nacional pela Alfabetização na Idade Certa à formação de professores alfabetizadores para a Educação Inclusiva. O objetivo da pesquisa foi o de levantar junto aos professores cursistas as principais modificações nas suas práticas pedagógicas após a participação neste programa de formação de professores implementado pelo Ministério da Educação (MEC), no que tange à alfabetização dos alunos público-alvo da educação especial. Utilizamos como metodologia a pesquisa de campo para o levantamento dos dados e a Perspectiva Histórico Cultural, na sua análise. Concluímos que o PNAIC foi o primeiro curso de formação de professores alfabetizadores a abordar a Educação Inclusiva, possibilitando significativas contribuições à pratica pedagógica de seus participantes.

PALAVRAS-CHAVE: Formação de professores. Educação inclusiva. PNAIC. Alfabetização.

RESUMEN: Este estudio analiza las contribuciones del Pacto Nacional por la Alfabetización en la Edad Cierta a la formación del profesorado alfabetizador para la Educación Inclusiva. El objetivo de la investigación fue el de levantar junto a los profesores cursistas, los principales cambios en sus prácticas pedagógicas, tras la participación en este programa de formación del profesorado implementado por el Ministerio de Educación $(M E C)$, en lo que se refiere a la alfabetización de los alumnos público objetivo de la educación especial. Utilizamos como metodología la investigación de campo para el levantamiento de los datos y la Perspectiva Histórico Cultural, en su análisis. Concluimos que el PNAIC fue el primer curso de formación del profesorado alfabetizador a abordar la

\footnotetext{
${ }^{1}$ Universidade Estadual de Maringá (UEM), Maringá - PR - Brasil. Doutora em Educação. Professora da Rede Estadual de Ensino do estado do Paraná. ORCID <https://orcid.org/0000-0001-7725-6053>. E-mail: ldalagobarreto@gmail.com

${ }^{2}$ Universidade Estadual de Maringá (UEM), Maringá - PR - Brasil. Pós-Doc em Letras. Professora do Programa de Pós Graduação em Educação. ORCID <https://orcid.org/0000-0002-2225-5667>. E-mail: emshimazaki@uem.br
} 
Educación Inclusiva posibilitando significativas contribuciones a la práctica pedagógica de sus participantes.

PALABRAS CLAVE: Formación del profesorado. Educación inclusiva. PNAIC. Alfabetización.

ABSTRACT: The present study analyzes the contributions of the National Pact for Alphabetization in the Right Age (PNAIC) to the training of alphabetizing teachers for the Inclusive Education. The goal of the research was to uplift, together with the 'teacherstudents', the main changes in their pedagogical practices, after their participation in this program of teacher formation implemented by the Ministry of Education (MEC), concerning the alphabetization of the target audience in special education. We utilized, as methodology, the field research for the raising of data and the Historical and Cultural Perspective in the analysis of the data. We have concluded that the PNAIC was the first course in the training of alphabetizing teachers to broach the Inclusive Education, enabling significant contributions to the pedagogical practice of its participants.

KEY WORDS: Teacher formation. Inclusive education. PNAIC. Alphabetization.

\section{Introdução}

Em 2012, o governo federal implementou o Pacto Nacional pela Alfabetização na Idade Certa (PNAIC), legalizado por portarias, medidas provisórias, leis e resoluções, dentre as quais as Portarias $n^{\circ} .1458$, de 14 de Dezembro de 2012; $n^{\circ} .867$, de 4 de julho de 2012 e $\mathrm{n}^{\circ} .90$, de 6 de fevereiro de 2013, que deliberam sobre a formação continuada dos professores alfabetizadores em nosso país e o atendimento das metas estabelecidas pela conferência de Dakar, cujo foco é a alfabetização de todas as crianças de até 8 anos de idade, isto é, até o final do terceiro ano do ensino fundamental.

Tais documentos normatizam a Formação Continuada de Professores Alfabetizadores, objetivando a sistematização do ensino da Língua Portuguesa e da Matemática, nos anos iniciais do Ensino Fundamental, compreendidas como os $1^{\circ}, 2^{\circ}$ e $3^{\circ}$ anos; e a realização de avaliações anuais, pelo Instituto Nacional de Estudos e Pesquisas Educacionais Anísio Teixeira (INEP), junto aos concluintes do $3^{\circ}$ ano,

Para a efetivação do Programa o governo estabeleceu convênio, que chamou de pacto, com os entes federados, isto é, os Estados da Federação, Distrito Federal e Municípios que se comprometeram a cumprir o estabelecido nas legislações que amparam o programa (BRASIL, 2012a). Estabeleceu também pacto com as instituições públicas de ensino superior que têm 
como função atender e implementar a formação dos professores por meio de grupos de estudos, professores esses que formam novos grupos e estudam nos municípios de origem.

Os governos, ao aderirem ao programa, comprometeram-se a alfabetizar todas as crianças até os 8 anos em Língua Portuguesa e Matemática, bem como realizar avaliações anuais junto aos alunos concluintes do $3^{\circ}$ ano do Ensino Fundamental, de modo a avaliar se as ações iniciais objetivadas estão, ou não, sendo atingidas. Tais ações foram organizadas em quatro eixos de atuação:

Formação continuada presencial para os professores alfabetizadores e seus orientadores de estudo; 2. Materiais didáticos, obras literárias, obras de apoio pedagógico, jogos e tecnologias educacionais; 3. Avaliações sistemáticas; 4. Gestão, mobilização e controle social (BRASIL, 2012a, p. 5).

As avaliações sistemáticas do programa, com o objetivo de mensurar se tais metas relacionadas à alfabetização e letramento estão, ou não, sendo atingidas, são realizadas anualmente por meio da Avaliação Nacional da Alfabetização (ANA), organizada pelo Instituto Nacional de Estudos e Pesquisas Educacionais Anísio Teixeira (INEP) e aplicada junto aos alunos do $3^{\circ}$ ano do Ensino Fundamental. As avaliações são compostas de 20 questões em cada área, sendo 17 itens de múltipla escolha e 3 itens discursivos em Língua Portuguesa, e 20 itens também de múltipla escolha, em Matemática.

$\mathrm{Na}$ área de Língua Portuguesa são avaliadas as habilidades de leitura, como a leitura de palavras com estrutura canônica e não canônica, o reconhecimento da finalidade do texto, a localização de informações explícitas, a capacidade de realizar inferências e o estabelecimento de relações entre as partes e o todo. Em relação à escrita são avaliadas as capacidades de escrever convencionalmente palavras e textos atendendo aos gêneros solicitados, bem como a utilização dos elementos de coesão, coerência e aspectos gramaticais e ortográficos.

Em Matemática, de acordo com Manual do pacto $^{3}$, são verificados os conhecimentos relacionados aos quatro eixos: Eixo Numérico e Algébrico, Eixo da Geometria, Eixo de Grandezas e Medidas e o Eixo de Tratamento da Informação, sendo avaliadas as habilidades de associação, contagem, comparação e ordenamento de quantidades e números naturais; a resolução de problemas e o cálculo envolvendo a adição e a subtração; a identificação e o reconhecimento das figuras geométricas planas e espaciais; a identificação, a leitura, a

\footnotetext{
${ }^{3}$ Disponível em: http://pacto.mec.gov.br/images/pdf/cadernosmat/PNAIC_MAT_Apresentaao_pg001-072.pdf
} 
comparação, o relacionamento, a ordenação dos sistemas de medidas e a identificação de informações em gráficos e tabelas.

São objetivos da ANA:

i) avaliar o nível de alfabetização dos educandos no $3^{\circ}$ ano do ensino fundamental; ii) produzir indicadores sobre as condições de oferta de ensino; iii) concorrer para a melhoria da qualidade do ensino e redução das desigualdades, em consonância com as metas e políticas estabelecidas pelas diretrizes da educação nacional (BRASIL, 2013, p. 7).

Mais uma vez encontramos, nesse documento, o cumprimento das metas estabelecidas pelas políticas públicas, em nosso país, reafirmando a necessidade da melhoria nos índices de alfabetização. Desse modo, a formação continuada é realizada inicialmente pelas universidades credenciadas ${ }^{4}$, para os professores denominados de Orientadores de Estudo, selecionados dentre os profissionais do quadro próprio das redes municipais e estaduais, os quais realizam o curso de 200 horas por ano, durante dois anos; posteriormente, organizam grupos de estudo junto aos professores alfabetizadores, participantes do programa, em seus municípios de origem. O curso foi presencial para os professores alfabetizadores, com carga horária de 120 horas por ano, e sua metodologia priorizou estudos e atividades práticas organizadas pelos Orientadores de Estudo, respaldando-se nos Cadernos de Estudo das áreas de Língua Portuguesa, Matemática e Educação Inclusiva, organizados pelo Ministério da Educação e distribuídos aos professores inscritos no Programa.

\section{Composição do Pacto Nacional pela Alfabetização na Idade Certa}

O Programa, com 5 anos de existência, até a presente data, é composto de 61 cadernos de formação ${ }^{5}$ escritos por especialistas nas áreas, de diferentes instituições de ensino do país, que estão disponibilizados online, cujos principais conteúdos abordados são: alfabetização em Língua Portuguesa, alfabetização matemática, formação de professores alfabetizadores, avaliação em alfabetização, currículo, planejamento, educação do campo e educação inclusiva.

Os cadernos, organizados sobre esses temas, estão subdivididos em cada ano de formação: Cadernos de Alfabetização em Língua Portuguesa (2013), Cadernos de alfabetização Matemática (2014) e Cadernos de Alfabetização (2015). Abordam de forma

${ }^{4}$ No total são 38 universidades formadoras do PNAIC, 32 federais e 6 estaduais, em todo o Brasil. Disponível em: http://pacto.mec.gov.br/images/pdf/Cadernos_2015/cadernos_novembro/pnaic_cad_apresentacao.pdf ${ }^{5}$ Disponíveis em: http://pacto.mec.gov.br/2012-09-19-19-09-11. 
transversal os conteúdos específicos dos três anos do ciclo de alfabetização, em oito unidades referentes a cada etapa.

Em 2012 foram disponibilizados 24 cadernos de Alfabetização em Língua Portuguesa. Em 2014 foram publicados 13 cadernos de Alfabetização Matemática. E, no ano de 2015 os cadernos priorizaram a interdisciplinaridade relacionando a alfabetização em Língua Portuguesa e Matemática, sendo 13 em Língua Portuguesa e 13 em Matemática.

A educação do campo é abordada em oito cadernos e a educação inclusiva, foco de nossa discussão, em dois cadernos específicos: “A alfabetização de crianças com deficiência: uma proposta inclusiva" (BRASIL, 2012b) e "Educação matemática inclusiva" (BRASIL, 2014).

A Educação Inclusiva também é abordada transversalmente, nos demais, com o objetivo de promover a reflexão acerca da importância das adaptações curriculares em todas as áreas do conhecimento, como meio de promoção da inclusão educacional. Em suma, de todas as características do PNAIC destacamos a relação teórico-prática como uma das principais contribuições, no que se refere a esta promoção.

\section{Modificações na prática inclusiva dos cursistas após a formação do PNAIC}

A pesquisa foi aprovada pelo Comitê Permanente de Ética em Pesquisa com Seres Humanos da Universidade Estadual de Maringá (COPEPE) sob o parecer $n^{\circ}$ 1.434.239. Um dos aspectos analisados nesta pesquisa diz respeito às principais modificações na prática inclusiva dos 39 professores entrevistados, pertencentes a 10 municípios selecionados dentre um grupo de 174, dos quais 5 com maiores escores e 5 com menores escores, obtidos na Avaliação Nacional da Alfabetização (ANA). A entrevista semiestruturada foi realizada, pessoalmente, após a formação realizada pelo Pacto Nacional pela Alfabetização na Idade Certa (PNAIC), coordenado pela Universidade Estadual de Maringá (UEM), na região Noroeste do estado do Paraná, locus da pesquisa.

Figura 1 - As modificações nas práticas dos professores após o PNAIC 


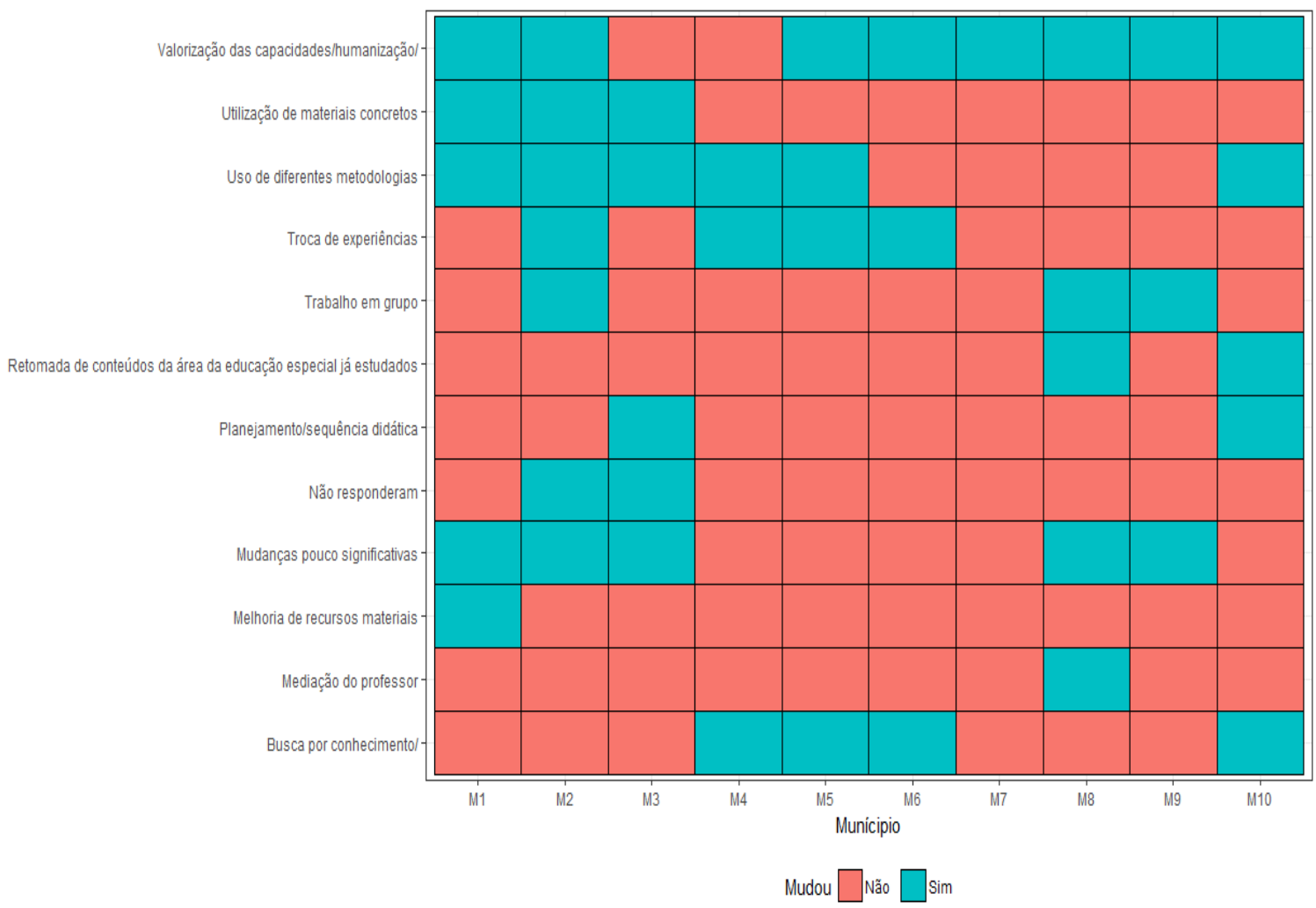

Fonte: Elaboração própria

Observamos, na Figura, que a modificação mais significativa, após a realização do Pacto Nacional pela Alfabetização na Idade Certa (PNAIC), foi a valorização das capacidades/humanização, a aceitação, o olhar diferenciado, a responsabilidade, a paciência pedagógica, caracterizada pelos entrevistados como o respeito aos limites e a temporalidade em que se processa a aprendizagem, citados como elementos de uma mesma categoria por 80\% dos municípios. Evidenciamos, ao mesmo tempo, que algumas alterações apresentaram uma única implementação, como a melhoria de recursos materiais e a mediação do professor. Notamos que o município M2 apresentou um número maior de modificações, 6 das 11 citadas por todo o grupo de entrevistados.

Este foi um avanço significativo em relação à apropriação dos conceitos abordados ao longo do curso, analisados por meio da entrevista, seleção de excertos dos projetos, relatórios e conversação com formadores, visto ser a educação um dos elementos fundamentais ao processo de humanização dos sujeitos. A compreensão das diferenças em relação ao tempo e a forma de aprendizagem, especialmente dos alunos público-alvo da Educação Especial, faz com que o professor diminua sua ansiedade e aprenda a lidar com as frustrações inerentes à alfabetização desses alunos. 
Nos cadernos do PNAIC, o respeito às limitações dos alunos público-alvo da Educação Especial é bastante enfatizada, por exemplo, no caderno "Educação Inclusiva" (BRASIL, 2014a, p. 27), a deficiência deixa de ser concebida "[...] como dificuldade exclusiva da pessoa deficiente (perspectiva quantitativa da inteligência), passando a ser considerada como limitações do contexto social que deve buscar e ofertar os apoios que ela necessita”, ou seja, a sua inclusão demanda mediações específicas que possibilitem a esse aluno se apropriar dos conceitos científicos mais complexos.

A materialização desses conceitos é exemplificada no relato apresentado nesse caderno, da professora Gabriela junto a um aluno com deficiência física:

\begin{abstract}
“[...] Bruno, com deficiência física - comprometimento motor e da fala - pode aprender conteúdos escolares e participar das aulas desde que seja provido de recursos e intervenções necessárias para sua comunicação e acessibilidade, neste caso o uso da prancha de comunicação, uma das ferramentas de Tecnologia Assistiva (TA) [...]" (BRASIL, 2014a, p. 55).
\end{abstract}

Outro exemplo dessa materialização encontramos no Caderno "Currículo na perspectiva da inclusão e da diversidade: as Diretrizes Curriculares Nacionais da Educação Básica e o Ciclo de Alfabetização" (BRASIL, 2015e, p. 38-39), relatada pela professora Diana, responsável por uma Sala de Recursos Multifuncionais há quatro anos, no Centro Educacional de Atividades integradas (CEAi) João Pereira de Assis de Campina Grande PB:

\footnotetext{
"Tenho aplicado vários recursos que estão disponibilizados na sala, entre eles: jogos educativos, pranchas, lupas, livros em Braille, livros em áudio, softwares educativos, várias ferramentas de informática e, quando necessário, confecciono recursos para garantir a todos o direito à aprendizagem. Muito tenho me alegrado com os pequenos avanços, que esses alunos apresentam no dia a dia, entre eles com deficiência intelectual, que exibem variados graus de dificuldades de aprendizagem $[\ldots] "$.
}

A formação realizada pela Universidade Estadual de Maringá, em 2015, referente aos cadernos do PNAIC “A criança no ciclo de alfabetização" e "Interdisciplinaridade no ciclo de alfabetização", também priorizou a valorização das capacidades/humanização, a aceitação, o olhar diferenciado e o planejamento do professor quanto à sistematização de mediações junto aos alunos público-alvo da Educação Especial, ao discutir tais aspectos nos grupos de estudo "Infância e Educação Inclusiva", organizados pelos formadores junto aos orientadores de estudo, por meio da leitura dos cadernos, discussão e relatos de suas experiências junto aos 
professores dos municípios participantes, os quais organizaram o projeto didático "Alfabetização e Letramento: Literatura Infantil e diversidade".

As discussões primaram pela importância de se compreender o currículo sob uma perspectiva interdisciplinar, priorizando a diversidade nas diferentes áreas do conhecimento, dentre elas, Língua Portuguesa, Ciências e Matemática, destacando-se as concepções de criança, infância e educação inclusiva como forma de superação de um ensino fragmentado e desarticulado. A sistematização de projetos possibilita essa articulação quando aborda o mesmo conteúdo, nas diferentes áreas do conhecimento.

Em relação ao respeito aos limites de aprendizagem apresentados pelos alunos público-alvo da Educação Especial e também nominados pelos professores de paciência pedagógica, devemos analisar com maior cautela para não incorrermos no risco de "limitar" demasiadamente o desenvolvimento cognitivo de nossos alunos, uma vez que o cérebro humano possui a capacidade de plasticidade neural. Beraldo (2007), ao pesquisar tal capacidade cerebral, especialmente nos anos iniciais da infância, atribui à internalização da linguagem um papel fundamental, pois desempenha a função de elemento mediador no desenvolvimento das funções psicológicas superiores e do psiquismo, ao afirmar que a principal especificidade do sistema nervoso é sua neuroplasticidade, a qual possibilita "[...] a função compensatória do cérebro em reorganizar os sistemas funcionais; e a transformação dos processos fisiológicos elementares em processos complexos [...]” (BERALDO, 2007, p. 94).

A pesquisa é relevante à área da Educação, pois confirma a capacidade do cérebro em compensar áreas menos desenvolvidas, ou lesionadas, em pessoas com deficiência, como ensina Vygotski (1983) ao comprovar que a internalização da linguagem verbal realiza a reorganização dos sistemas funcionais denominados pelo autor de centros superiores, de modo a substituírem a função da área lesionada, para possibilitar ao indivíduo a realização de uma mesma atividade, utilizando outras funções. Por exemplo, o cego realiza a compensação da sua deficiência com o aumento dos estímulos nervosos em outras áreas cerebrais e por meio "[...] do exercício da observação, evolução e análise das diferenças, [...] a deficiência se compensa por completo, ou em parte, com o intenso desenvolvimento de outra função [...]" (VYGOTSKI, 1983, p. 14), como a audição e o tato, de modo que a deficiência passa a ser concebida como força motriz. O mesmo ocorre com o surdo, ao desenvolver a linguagem gestual, e o deficiente intelectual, quando substitui operações psicológicas simples por outras mais complexas, ao internalizá-las por meio das relações de coletividade e recursos sociais utilizados nesse processo. 
A função da escola, nesse processo compensatório, é a de organizar um espaço de socialização de diferentes conhecimentos para oportunizar o processo de compensação das deficiências, ou mesmo distúrbios de aprendizagem apresentados por seus alunos. Ao se retomar o respeito pelos limites, citado pela maioria dos entrevistados, não podemos valorizar demasiadamente esta limitação, em virtude do desenvolvimento das suas capacidades, caso contrário, "[...] o meio social onde transcorre o processo de desenvolvimento lhe põe limites ao equívoco orgânico, a criação de uma "segunda natureza" (VYGOSTSKI, 1983, p. 17). A segunda natureza diz respeito à transformação de função/limitação em novas formações, resultantes do processo compensatório.

O preconceito escolar, muitas vezes velado, faz com que surja um sentimento de inferioridade nos alunos público-alvo da Educação Especial, pois dificulta o desenvolvimento de sua capacidade compensatória. Esse preconceito é externalizado nas falas de professores, como "não podemos reprová-los, pois têm deficiência" ou "temos que compreender que eles têm uma limitação".

Outro aspecto citado pelos professores foi a necessidade que sentem em discutir seus medos e angústias entre seus pares, de forma a compartilhar suas experiências e promover um diálogo entre si, demandando a elaboração de espaços de formação continuada que favoreçam o diálogo e a reflexão coletiva acerca das mediações pedagógicas necessárias à criação dessa "segunda natureza".

Chamou-nos muita a atenção o fato de 5 municípios (M1, M2, M3, M8 e M9) terem citado "alterações pouco significativas", evidenciando diferentes pontos de vista em relação ao curso, nos mesmos grupos, como demonstram as falas de participantes dos municípios M1, M2 e M3:

M1: "Foi pouco tempo de curso e superficial".

M1: "A gente tem mais recursos e materiais diversificados. Se a criança não aprende de um jeito, aprende de outro".

M2: "Muito vago. Discutiu-se muito a aceitação do professor e os problemas e pouco as alternativas para resolvê-los".

M2: "A discussão em grupo possibilitou a troca de experiências e a busca de caminhos para resolver os problemas".

M3: "O PNAIC deveria trazer mais discussões sobre a prática".

M3: "É um curso mais prático, dinâmico e concreto".

M9: "Pouco tempo de curso".

M9: "Mudou a visão. O trabalho em grupo, antes trabalhava mais individual”. 
Concordamos que o tempo de formação é exíguo para discutir a Educação Especial, os aspectos inclusivos e outras demandas sobre a alfabetização. $\mathrm{O}$ tema deve ser estudado com maior propriedade, mas, por outro lado, é necessário que se discuta o acesso ao conhecimento de todas as pessoas, sejam elas deficientes ou não.

Verificamos um discurso contrário no município M10, ao destacar a retomada de conteúdo, o trabalho em grupo, o planejamento e a busca por novos conhecimentos, como alterações significativas elencadas após a realização do programa:

M10: "A paciência pedagógica, o respeito aos limites e a valorização das capacidades".

M10: "Gostei porque clareou como melhor trabalhar diferentes metodologias".

M10: "Trabalhou a humanização, a nos colocarmos no lugar do outro e a importância do planejamento mais adequado”.

Tal contradição entre as respostas dos participantes e a opção por "alterações pouco significativas" indica que esses participantes, ou já se apropriaram do conteúdo discutido ao longo da formação, ou recusam-se a mudar suas práticas pedagógicas enraizadas ao longo de sua carreira profissional, afinal, mudar implica estar aberto a novas expectativas de aprendizagem, ao mesmo tempo, à necessidade de sair de uma "zona de conforto", por meio de muito estudo e reflexão a respeito de suas ações.

\section{Considerações finais}

Concluímos com este estudo que o PNAIC possibilitou inúmeras contribuições à formação dos professores alfabetizadores, no que se refere, mais especificamente, à Educação Inclusiva, pois foi o primeiro curso implementado pelo Ministério da Educação a discutir transversalmente a alfabetização dos alunos público-alvo da Educação Especial.

Esta reflexão resultou em modificações teórico-práticas, materializadas nas falas de diferentes professores alfabetizadores cursistas do PNAIC evidenciando a apropriação de alguns conceitos da Perspectiva Histórico Cultural, como a valorização das capacidades dos alunos, em detrimento de suas limitações e dificuldades de aprendizagem, como processo de compensação e humanização (VYGOSTSKI, 1983).

Salientamos a importância de políticas públicas de formação de professores voltadas a reflexões, que primem pela igualdade de oportunidades e valorizem o direito dos alunos público-alvo da educação especial de aprender e ser efetivamente alfabetizados. 


\section{REFERÊNCIAS}

BERALDO, Christiane Aparecida. Educação Infantil: mediação, aprendizagem e funções psicológicas. 108 f. Dissertação (Mestrado em Educação). Universidade Estadual de Maringá. 2007.

BRASIL. Ministério da Educação. Portaria no 867 de 4 de julho de 2012. Institui o Pacto pela Educação na Idade Certa e as ações do Pacto e define suas diretrizes gerais. Disponível em: www.pacto.gov.br. Acesso em: 01 mar. 2017.

BRASIL. Ministério da Educação. Portaria no 1.458 de 14 de dezembro de 2012. Define categorias e parâmetros para a concessão de bolsas de estudo e pesquisa no âmbito do Pacto Nacional pela Alfabetização na Idade Certa. Disponível em: www.pacto.gov.br. Acesso em: 01 mar. 2017.

BRASIL. Ministério da Educação. Diretoria de Apoio à Gestão Educacional. Pacto nacional pela alfabetização na idade certa: formação de professores no pacto nacional pela alfabetização na idade certa. Brasília: MEC, SEB, 2012a.

BRASIL. Ministério da Educação. Secretaria de Educação Básica. Diretoria de Apoio à Gestão Educacional. Pacto nacional pela alfabetização na idade certa: A alfabetização de crianças com deficiência: uma proposta inclusiva. Brasília: MEC, SEB, 2012b. Disponível em: www.pacto.gov.br. Acesso em: 07 mar. 2017.

BRASIL. Instituto Nacional de Estudos e Pesquisas Educacionais Anísio Teixeira. Avaliação Nacional da Alfabetização (ANA): documento básico. Brasília, 2013. Disponível em: http://download.inep.gov.br/educacao_basica/saeb/2013/livreto_ANA_online.pdf. Acesso em: 01 fev. 2017.

BRASIL. Ministério da Educação. Secretaria de Educação Básica. Diretoria de Apoio à Gestão Educacional. Pacto Nacional pela Alfabetização na Idade Certa: Educação Inclusiva. Brasília: MEC, SEB, 2014. Disponível em:

http://pacto.mec.gov.br/images/pdf/cadernosmat/PNAIC_MAT_Educ\%20Incl_pg001096.pdf. Acesso em: 25 abr 2017.

BRASIL. Ministério da Educação. Secretaria de Educação Básica. Diretoria de Apoio à Gestão Educacional. Pacto Nacional pela Alfabetização na Idade Certa. Currículo na perspectiva da inclusão e da diversidade: as Diretrizes Curriculares Nacionais da Educação Básica e o ciclo de alfabetização. Brasília: MEC, SEB, 2015. Disponível em:

http://pacto.mec.gov.br/images/pdf/Cadernos_2015/cadernos_novembro/pnaic_cad_1_19112 015.pdf. Acesso em: 25 abr 2017.

VYGOTSKI, S.L. Obras Escogidas - V: fundamento de defectologia. Moscú: Editorial Pedagógica, 1983. 


\section{Como referenciar este artigo}

BARRETO, L. C. D.; SHIMAZAKI, E. M. A formação de professores alfabetizadores para a educação inclusiva: um destaque ao pacto nacional pela alfabetização na idade certa. Revista Ibero-Americana de Estudos em Educação, Araraquara, v. 14, n. 1, p. 157-168, jan./mar., 2019. E-ISSN: 1982-5587. DOI: 10.21723/riaee.v14i1.11067

Submissão: $21 / 02 / 2018$

Revisões requeridas: 30/05/2018

Aprovação final: 26/08/2018 